\title{
Adenocarcinoma of the Urinary Bladder
}

\author{
Mesane Adenokarsinomu
}

\author{
(D) Burçin Tuna \\ Dokuz Eylül University Faculty of Medicine, Department of Pathology, Izmir, Turkiye
}

\section{Introduction}

Primary adenocarcinoma of the bladder is malignant tumor with histologically pure glandular differentiation. It accounts for $0.5-2 \%$ of all primary bladder malignancies. This tumor is more common in men than in women. Patients are usually in the sixth-seventh decade of life. The tumor is very aggressive and metastatic disease is reported in $40 \%$ of patients at the time of diagnosis. Although the pathogenesis is uncertain, several risk factors have been described. Since it is often seen in mucosa adjacent to primary adenocarcinoma of the urinary bladder, intestinal metaplasia is thought to be precursor lesion. However, recent studies have shown that intestinal metaplasia was not associated with an increased risk for adenocarcinoma (1).

Bladder adenocarcinoma may be primary or secondary; secondary adenocarcinomas are more common than primary adenocarcinomas in the bladder. The most common origin of the secondary bladder adenocarcinoma is the colon, prostate, endometrium, cervix, breast and lung. Secondary involvement of the bladder occurs either by direct extension or by metastasis from a distant site (2).

The diagnosis of primary adenocarcinoma of the bladder should only be made when carcinoma shows pure glandular differentiation (3). Morphologically, adenocarcinoma of the bladder can be divided into intestinal (enteric) type and nonintestinal (non-enteric) type. Primary bladder adenocarcinoma exhibits several different growth patterns, including enteric, mucinous, signet-ring cell, not otherwise specified, and mixed patterns (4). The enteric (intestinal) type of adenocarcinoma consists of tall columnar tumor cells with abundant eosinophilic cytoplasm containing necrosis (Figure 1).
Mucinous adenocarcinoma of the bladder is a specific subtype and characterized by large lakes of extracellular mucin containing tumor cells (Figure 2). These mucinous foci should constitute at least half of the tumor mass for diagnosis. The prognosis varies with stage and, survival is better in tumors confined to the urinary bladder. However, low stage tumors are less frequent than $30 \%$ of all tumors (5).

Signet ring cell adenocarcinoma is another rare morphological subtype of primary adenocarcinoma of the bladder. For establishing diagnosis, there should be at least focal signet ring cell differentiation with an adenocarcinoma without evidence of urothelial carcinoma. The signet ring cells within the tumor are characterized by plasmocytoid or monocytoid appearance or have the classic signet ring cell morphology (Figure 3). Pure signet ring cell adenocarcinoma is extremely rare and the prognosis is very poor $(6,7)$.

The most important and difficult problem is to differentiate these tumors from metastatic adenocarcinoma from other organs such as colon, lung, prostate, breast and uterus. The most common secondary tumor to involve the urinary bladder is colon adenocarcinoma. Morphologically, it is similar to enteric type bladder adenocarcinoma. For this reason, for correct diagnosis, it is very important that pathologists obtain adequate clinical information. Immunohistochemical methods may help distinguish between these two tumors in some cases.

The immunohistochemical staining pattern of primary adenocarcinoma of the bladder is variable and usually similar to that of colon adenocarcinoma. Immunohistochemistry has limited utility in differentiating primary bladder adenocarcinoma from metastatic colon adenocarcinoma $(8,9,10)$. Expression of cytokeratin 7 is variable and cytokeratin 20 is mostly stained with adenocarcinoma of the bladder. The CDX2 nuclear

Correspondence: Burçin Tuna MD, Dokuz Eylül University Faculty of Medicine, Department of Pathology, İzmir, Turkiye Phone: +90 2324123411 E-mail: tunaburcin65@gmail.com ORCID-ID: orcid.org/0000-0002-4195-5167 Received: 09.08.2018 Accepted: 06.09.2018

Cite this article as: Tuna B. Adenocarcinoma of the Urinary Bladder. J Urol Surg 2018;5(4):233-238.

๑Copyright 2018 by the Association of Urological Surgery / Journal of Urological Surgery published by Galenos Publishing House. 


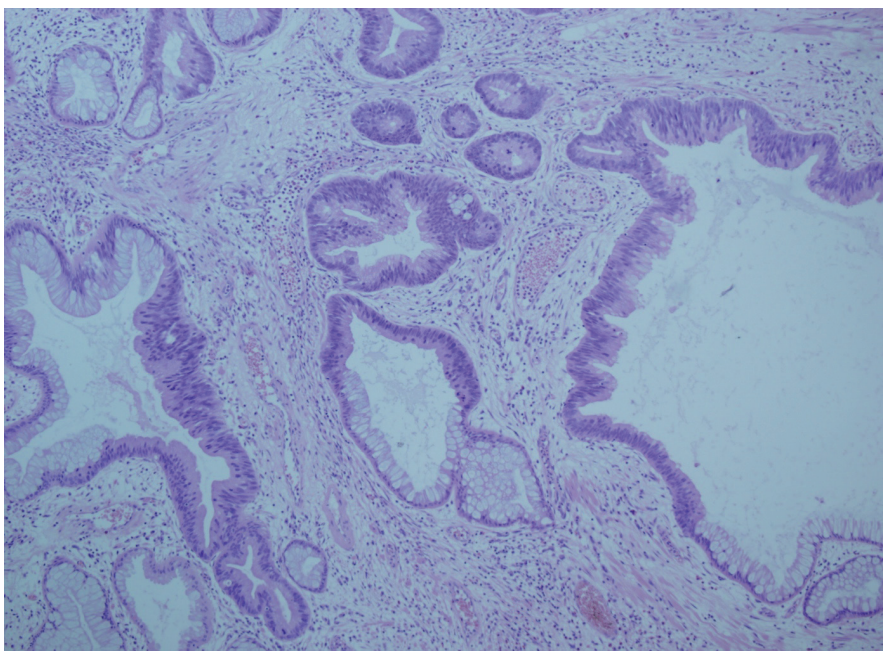

Figure 1. Enteric type primary adenocarcinoma of the bladder, which is often indistinguishable from colorectal adenocarcinoma (hematoxylin and eosin, original magnifications, 200x)

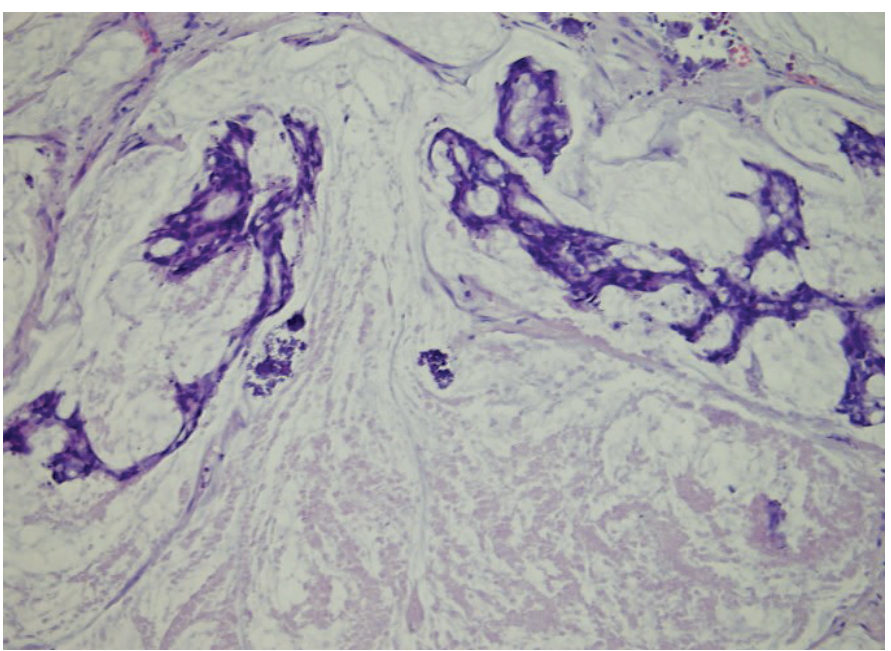

Figure 2. Mucinous-type bladder adenocarcinoma produces abundant extracellular mucin, pool of mucin with floating tumor cells (hematoxylin and eosin, original magnifications, 200x)

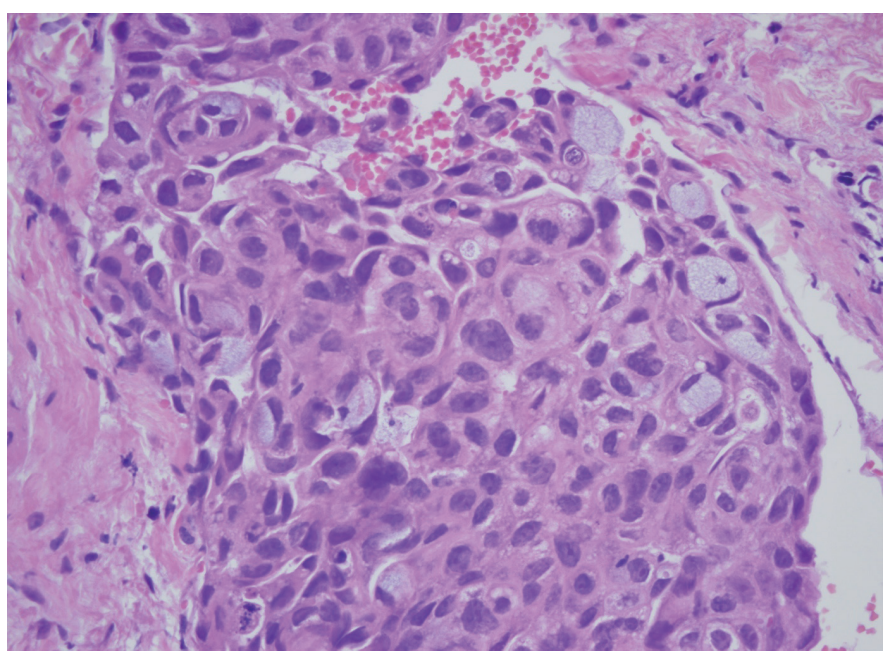

Figure 3. Signet ring cell-type bladder adenocarcinoma (hematoxylin and eosin, original magnifications, 200x) transcription factor, which is an intestinal marker, may also be misleading because it also stains bladder adenocarcinomas. Nuclear B-catenin staining is typical of colorectal carcinomas (81\%), whereas primary bladder adenocarcinoma shows limited cytoplasmic staining.

Clear cell adenocarcinoma (CCA) is a very unique variant that forms $0.5-2 \%$ of all bladder carcinomas (11). The term CCA should be reserved for tumors resembling CCA of the female genital tract (12). Unlike other bladder adenocarcinomas, CCA affects women more than men. CCA is common in female urethra, but it can also be seen in men and in the urinary bladder. Hematuria and dysuria are the most common clinical findings. CCA may be associated with endometriosis or müllerianosis $(11,13)$. It can also be seen within a urinary bladder diverticulum. CCA consists of cells with abundant clear cytoplasm containing glycogen in the form of tubules, cysts, papillary structures or diffuse sheets (Figure 4). The tumor cells lining tubules or cysts may be cuboidal, hobnail or flattened (Figure 5). It usually shows

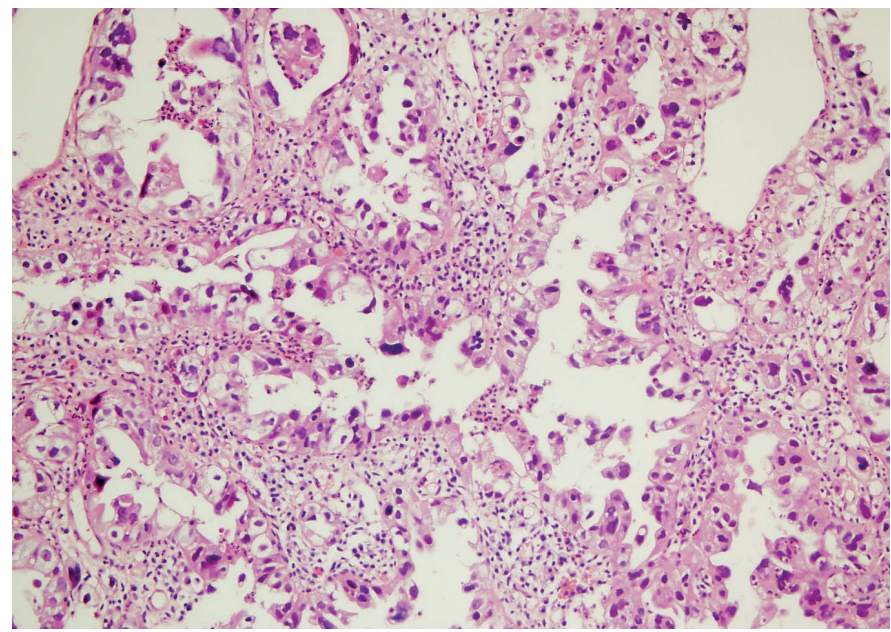

Figure 4. Clear cell adenocarcinoma exhibits tubulocystic and papillary growth patterns (hematoxylin and eosin, original magnifications, 200x)

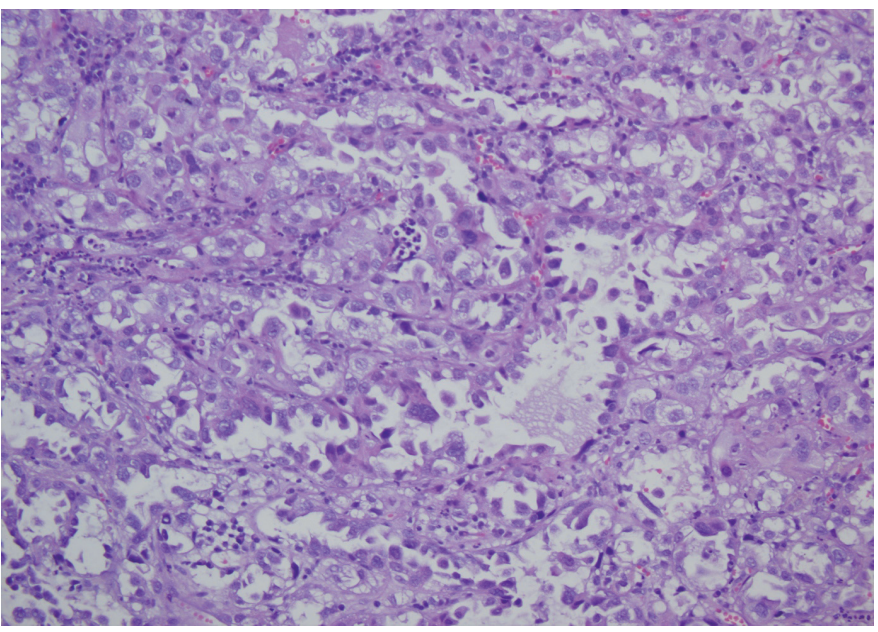

Figure 5. Hobnail or cuboidal tumor cells in clear cell adenocarcinoma (hematoxylin and eosin, original magnifications, 200x) 
strong immunostaining for PAX8 (Figure 6). The differential diagnosis of CCA includes benign reactive processes, primary malign tumors and metastatic tumors of the bladder (14). The benign process which is the most common problem especially in biopsies is the nephrogenic adenoma. Nephrogenic adenoma, unlike bladder CCA, is more common in males and is usually small sized lesion.

CCA can also develop in other organs such as the prostate, lung, breast, uterus, ovary and vagina. Before establishing the diagnosis, metastatic melanoma, clear cell sarcoma and seminoma should be excluded. To exclude these possibilities, negative staining of tumor cells with S100, human melanoma black-45, CD117 and placental alkaline phosphatase and positive staining with cytokeratin 7 will support carcinoma diagnosis. Cancer antigen-125 expression is insufficient to show müllerian

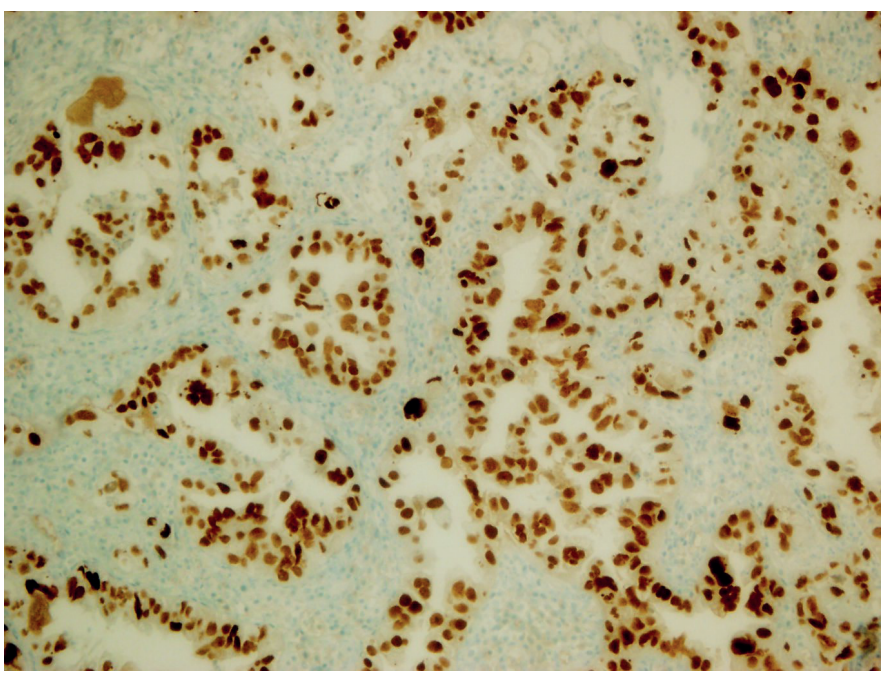

Figure 6. The carcinoma cells show nuclear immunreactivity with PAX8 (immunohistochemistry, original magnifications, 200x)

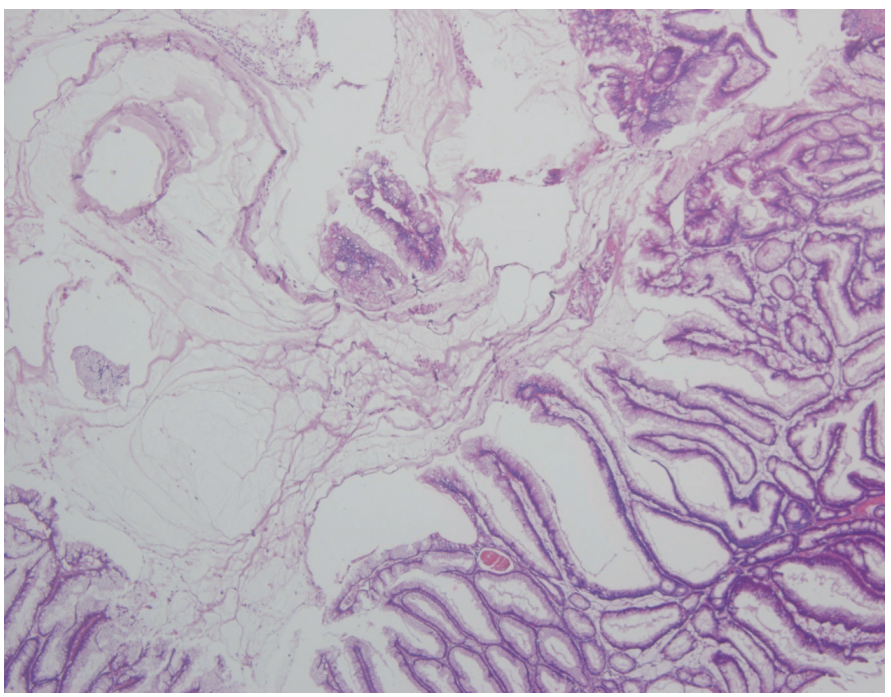

Figure 7. Urachal adenocarcinoma which is indistinguishable from nonurachal carcinoma (hematoxylin and eosin, original magnifications, 200x) origin. As a result, bladder CCA has a different morphology, resembling clear cell carcinoma of müllarian origin (15).

Urachal adenocarcinoma; primary adenocarcinoma of the bladder accounts for less than $1 \%$ of all bladder malignancies, of these $20-39 \%$ are of urachal origin $(16,17)$. Urachal adenocarcinoma is a special tumor developing within the urachal remnants of the bladder dome. Bladder involvement is often a secondary occurrence. Urachal remnant is the residual tissues of the embryonic allantoic sac associated with umbilicus. Urachal adenocarcinoma is more common in men and tends to occur in the fifth and sixth decades of life. Common symptoms are hematuria, pain, symptoms of irritative voiding, and mucosuria (16). The diagnosis of urachal adenocarcinoma is a diagnosis of exclusion. The possibility of primary or secondary non-urachal adenocarcinoma should be excluded $(18,19)$.

Urachal adenocarcinoma has various morphological features (Figure 7). However, none of these features are highly specific to distinguish urachal and non-urachal tumors $(3,20)$. Different diagnostic criteria for urachal adenocarcinoma have been defined. The most practical diagnostic criteria include localization in the bladder dome, sharp transition between tumor and benign surface urothelium, and exclusion of the possibility of adenocarcinoma elsewhere in the bladder (20). The prognosis of urachal adenocarcinoma is not significantly different from nonurachal adenocarcinoma (16). The immunohistochemical staining pattern of urachal adenocarcinoma shows a significant overlap with metastatic colorectal adenocarcinoma as well as primary bladder adenocarcinoma. Almost all urachal adenocarcinomas express CK20 and CDX2. They also show variable expression of CK7, $\beta$-catenin and high-molecular-weight cytokeratin (HMWK) (18). Immunohistochemical markers are insufficient to distinguish between colorectal adenocarcinoma and urachal adenocarcinoma. Diffuse HMWK staining supports the diagnosis of urachal adenocarcinoma, whereas diffuse nuclear $\beta$-catenin staining supports that of colorectal origin. However, exclusion of colorectal metastases is a critical step in the diagnosis.

\section{Secondary Adenocarcinoma}

Secondary tumors of the bladder are rare and constitute less than $2 \%$ of all bladder tumors. Although bladder is not a common area for metastatic adenocarcinoma, secondary adenocarcinoma is more frequent than primary adenocarcinoma (20). The bladder is involved with various malignancies as a secondary tumor. It has been reported that the commonest sites of tumors spreading to the bladder were colon (21\%), prostate (19\%), rectum (12\%), and cervix $(11 \%)(2,21,22,23)$. Tumors that spread to the bladder are most commonly located on the bladder neck and trigon. It may be difficult to differentiate secondary adenocarcinomas from primary adenocarcinomas of the bladder. The histological 
features combined with results of immunohistochemistry and clinical history help obtain accurate diagnosis. For this reason, knowledge of the history and clinical findings are particularly important in the diagnosis of non-urothelial carcinomas that are metastatic to the urinary bladder.

The most common secondary malignancy involving the urinary bladder is colorectal adenocarcinoma (Figure 8a). Although it has been suggested that immunohistochemical markers such as CK7, CK20, villin, CDX-2 and $\beta$-catenin help resolve the differential diagnosis of these tumors, sensitivity and specificity limitations have prevented any single marker or marker panel from appearing as superior $(24,25,26,27,28)$. A panel of CK7, CK20, $\beta$-catenin and thrombomodulin has some value in distinguishing primary bladder adenocarcinoma from metastatic colorectal adenocarcinoma. Primary bladder adenocarcinoma is usually positive for CK7 and thrombomodulin and shows membranous staining for $\beta$-catenin, while a nuclear $\beta$-catenin and CK20 positive staining favor colorectal origin (20). However, the possibility of colonization of urothelial mucosa of the bladder with a well-differentiated colonic adenocarcinoma secondary to intestinal metaplasia/dysplasia should be kept in mind. In most cases, however, clinical history and colonoscopic findings are the most important for accurate diagnosis.
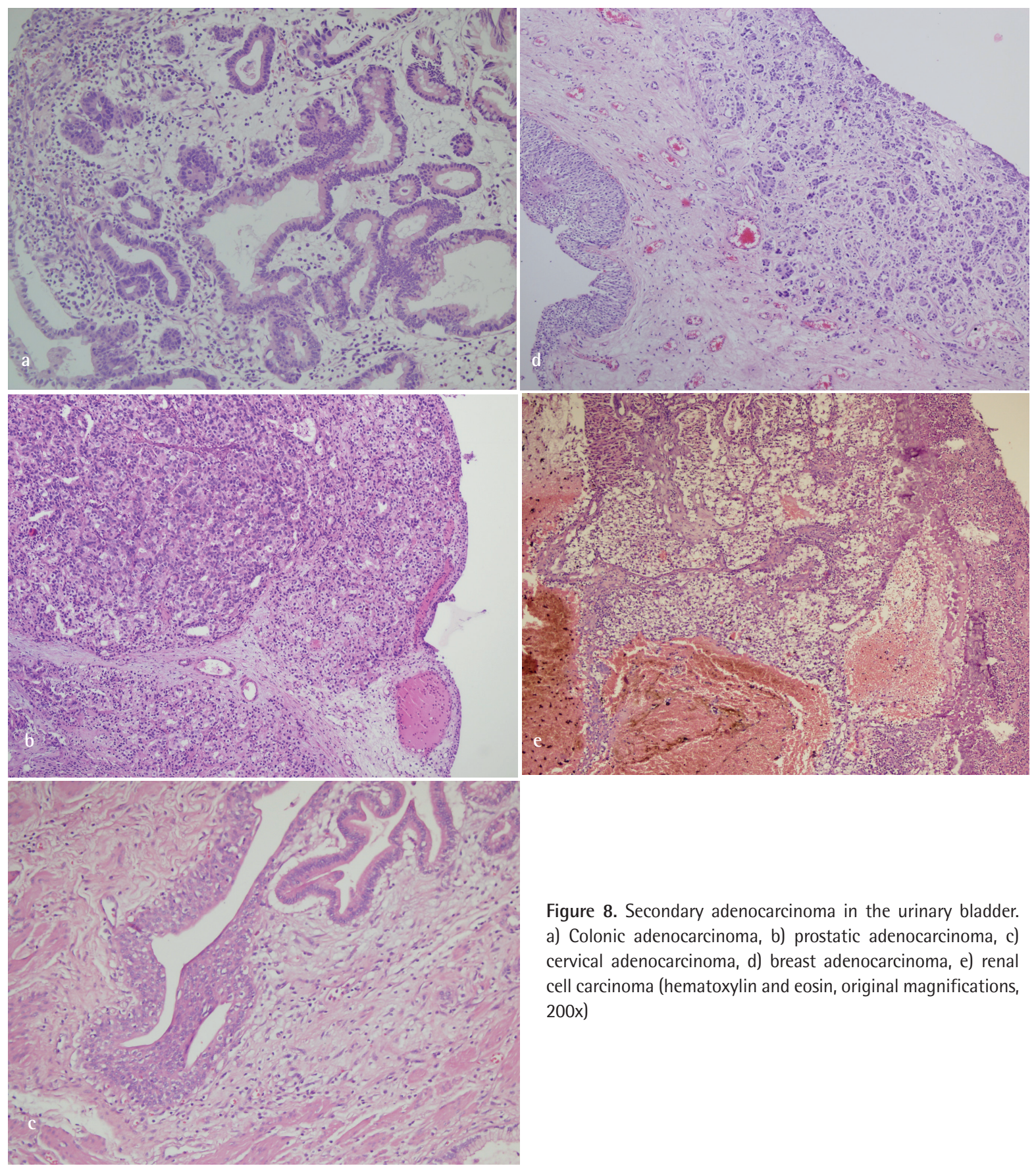

Figure 8. Secondary adenocarcinoma in the urinary bladder. a) Colonic adenocarcinoma, b) prostatic adenocarcinoma, c) cervical adenocarcinoma, d) breast adenocarcinoma, e) renal cell carcinoma (hematoxylin and eosin, original magnifications, 200x) 
The second most common secondary malignancy involving the bladder is prostatic adenocarcinoma (Figure 8b). Prostatic adenocarcinoma often involves the bladder by direct invasion because of its close proximity. It is important to differentiate prostate adenocarcinoma from bladder adenocarcinoma because they are managed differently (20). In most cases, prostatic adenocarcinoma has distinct morphology and is easily identifiable by histology alone. However, in difficult cases, basal cell markers, such as $34 \beta \mathrm{E} 12$ cytokeratin (HMWK) and p63, are usually negative in prostate cancer, whereas prostate-specific antigen (PSA) immunostaining is positive in approximately $90 \%$ of prostate cancer cases. Although most of the prostate adenocarcinomas express PSA and prostate-specific acid phosphatase (PSAP), some poorly differentiated or previously treated prostate adenocarcinomas may not be positive for PSA and PSAP in immunohistochemical analysis. In these cases, other prostate-specific markers, such as prostate-specific membrane antigen, prostein (P501S) and NKX3.1, may also be used in differential diagnosis. It is proposed to use antibodies panel instead of a single antibody to distinguish prostatic adenocarcinoma from bladder adenocarcinoma, especially in poorly differentiated tumors $(29,30,31,32,33)$.

Endometrial and cervical adenocarcinomas (Figure 8c) may involve the bladder by direct invasion. Endometrial carcinoma is usually positive for PAX8 and vimentin, whereas bladder adenocarcinoma does not express one or the other $(32,33)$. Although most endocervical adenocarcinomas are positive for p16 in immunohistochemical staining, some bladder adenocarcinomas also express p16. Correlation with the clinical history is important in resolving the tumor origin. Although most endocervical adenocarcinomas are positive for p16, some bladder adenocarcinomas also express $p 16$. Correlation with the clinical history is important to resolve the tumor origin.

Metastasis from other organs; metastasis to the bladder from breast (Figure 8d), lung, renal (Figure 8e) and other adenocarcinomas are rare. Since these metastatic adenocarcinomas show morphologic patterns overlapping with primary bladder adenocarcinoma, immunohistochemistry and clinical history will be necessary for definitive diagnosis $(2,34)$. When estrogen receptor and progesterone receptor are coexpressed, breast adenocarcinoma is favored. Bladder adenocarcinoma usually does not express GATA3, whereas breast adenocarcinoma is positive for GATA3 $(35,36)$.

Lung adenocarcinoma is positive for thyroid transcription factor-1, whereas bladder adenocarcinoma is negative. Rarely, renal cell carcinoma can metastasize to the bladder, which should be distinguished from CCA of the bladder. Since PAX2 and PAX8 are expressed in both tumors, they do not help in the differential diagnosis $(37,38)$. CD10, vimentin, carbonic anhydrase 9 and renal cell carcinoma are expressed in clear cell renal cell carcinoma whereas CK7 and CK20 are usually expressed in bladder CCA (39).

Majority of patients with primary bladder adenocarcinoma have a muscle-invasive disease and they are usually treated with radical cystectomy and pelvic lymph node dissection. Primary radiation therapy may be considered for some patients who are not candidates for cystectomy. The efficacy of primary radiation therapy compared to surgery is unclear due to the limited experience with this rare disease.

\section{Conclusion}

The diagnosis of bladder adenocarcinoma is clinically important due to the fact that the diagnosis of bladder adenocarcinoma initiates a clinical effort to exclude the possibility of secondary adenocarcinoma of the bladder with a different adenocarcinoma from a different region.

Keywords: Urinary bladder, Adenocarcinoma, Primary, Secondary

Anahtar Kelimeler: Mesane, Adenokarsinom, Primer, Sekonder

\section{Ethics}

Peer-review: Externally peer-reviewed.

Financial Disclosure: The author declared that this study received no financial support.

\section{References}

1. Smith AK, Hansel DE, Jones JS. Role of cystitis cystica et glandularis and intestinal metaplasia in development of bladder carcinoma. Urology 2008;71:915-918.

2. Bates AW, Baithun SI. Secondary neoplasms of the bladder are histological mimics of nontransitional cell primary tumours: clinicopathological and histological features of 282 cases. Histopathology 2000;36:32-40.

3. Zhong M, Gersbach E, Rohan SM, Yang XJ. Primary adenocarcinoma of the urinary bladder: differential diagnosis and clinical relevance. Arch Pathol Lab Med 2013;137:371-381.

4. Eble JN, Sauter G, Epstein JI, et al. eds. World Health Organization Classification of Tumours. Pathology and Genetics of Tumours of the Urinary System and Male Genital Organs. IARC Press: Lyon;2004:359.

5. Grignon DJ, Ro JY, Ayala AG, Johnson DE, Ordonez NG. Primary adenocarcinoma of the urinary bladder: a clinicopathologic analysis of 72 cases. Cancer 1991;67:2165-2172.

6. Bernstein SA, Reuter VE, Carroll PR, Whitmore WF Jr. Primary signet-ring cell carcinoma of urinary bladder. Urology 1988;31:432-436.

7. Poore TE, Egbert $B$, Jahnke R, Kraft JK. Signet ring cell adenocarcinoma of the bladder: linitis plastica variant. Arch Pathol Lab Med 1981;105:203-204.

8. Wang HL, Lu DW, Yerian LM, Alsikafi N, Steinberg G, Hart J, Yang XJ. Immunohistochemical Distinction Between Primary Adenocarcinoma of the Bladder and Secondary Colorectal Adenocarcinoma. Am J Surg Pathol 2001;25:1380-1387. 
9. Emerson RE, Cheng L. Immunohistochemical markers in the evaluation of tumors of the urinary bladder: a review. Anal Quant Cytol Histol 2005;27:301-316.

10. McKenney JK, Amin MB. The role of immunohistochemistry in the diagnosis of urinary bladder neoplasms. Semin Diagn Pathol 2005;22:69-87.

11. Abbas M, Kramer MW, Wolters M, Herrman TR, Becker JU, Kreipe HH. Adenocarcinoma of the urinary bladder, mesonephroid type: a rare case. Rare Tumors 2013;5:e3.

12. Amin $M B$, McKenney JK, Paner GP, Hansel DE, Grignon DJ, Montironi $R$, Lin 0 , Jorda M, Jenkins LC, Soloway M, Epstein Jl, Reuter VE; International Consultation on Urologic Disease-European Association of Urology Consultation on Bladder Cancer 2012. ICUD-EAU International Consultation on Bladder Cancer 2012: Pathology. Eur Urol 2013;63:16-35.

13. Liu, H, Leng J, Lang J and Cui $\mathrm{Q}$. Clear cell carcinoma arising from abdominal wall endometriosis: a unique case with bladder and lymph node metastasis. World J Surg Oncol 2014;12:51.

14. Loizzi V, Cormio G, Leone L, Falagario M, Longo S, Resta L, Selvaggi L. A rare case of primary clear-cell adenocarcinoma of the bladder arising from bladder endometriosis. J Obstet Gynaecol 2015;35:758-760.

15. Knez VM, Barrow W, Lucia MS, Wilson S, La Rosa FG. Clear cell urothelial carcinoma of the urinary bladder: a case report and review of the literature. J Med Case Rep 2014;8:275.

16. Hayes Ryan D, Paramanathan $P$, Russell N, Coulter J. Primary urachal malignancy: case report and literature review. Ir J Med Sci 2013;182:739-741.

17. Sirintrapun SJ, Ward M, Woo J, Cimic A. High-stage urachal adenocarcinoma can be associated with microsatellite instability and KRAS mutations. Hum Pathol 2014;45:327-330.

18. Gopalan A, Sharp DS, Fine SW, Tickoo SK, Herr HW, Reuter VE, Olgac S. Urachal carcinoma: a clinicopathologic analysis of 24 cases with outcome correlation. Am J Surg Pathol 2009;33:659-668.

19. Johnson DE, Hodge GB, Abdul-Karim FW, Ayala AG. Urachal carcinoma. Urology 1985;26:218-221.

20. Dadhania V, Czerniak B, Guo CC. Adenocarcinoma of the urinary bladder. Am J Clin Exp Urol 2015;3:51-63.

21. Lopez-Beltran A, Cheng L. Histologic variants of urothelial carcinoma: differential diagnosis and clinical implications. Hum Pathol 2006;37:13711388.

22. Melicow MM. Tumors of the urinary bladder: a clinico-pathological analysis of over 2500 specimens and biopsies. J Urol 1955;74:498-521.

23. Velcheti $V$ and Govindan R. Metastatic cancer involving bladder: a review. Can J Urol 2007;14:3443-3448.

24. Williamson SR, Lopez-Beltran A, Montironi R, Cheng L. Glandular lesions of the urinary bladder: clinical significance and differential diagnosis. Histopathology 2011;58:811-834.

25. Wang HL, Lu DW, Yerian LM, Alsikafi N, Steinberg G, Hart J, Yang XJ. Immunohistochemical distinction between primary adenocarcinoma of the bladder and secondary colorectal adenocarcinoma. Am J Surg Pathol 2001;25:1380-1387.

26. Tamboli $\mathrm{P}$, Mohsin SK, Hailemariam S, Amin MB. Colonic adenocarcinoma metastatic to the urinary tract versus primary tumors of the urinary tract with glandular differentiation: a report of 7 cases and investigation using a limited immunohistochemical panel. Arch Pathol Lab Med 2002;126:10571063.

27. Suh N, Yang XJ, Tretiakova MS, Humphrey PA, Wang HL. Value of CDX2, villin, and alpha-methylacyl coenzyme $A$ racemase immunostains in the distinction between primary adenocarcinoma of the bladder and secondary colorectal adenocarcinoma. Mod Pathol 2005;18:1217-1222.

28. Raspollini MR, Nesi G, Baroni G, Girardi LR, Taddei GL. Immunohistochemistry in the differential diagnosis between primary and secondary intestinal adenocarcinoma of the urinary bladder. Appl Immunohistochem Mol Morphol 2005;13:358-362.

29. Svanholm H. Evaluation of commercial immunoperoxidase kits for prostatic specific antigen and prostatic specific acid phosphatase. Acta Pathol Microbiol Immunol Scand A 1986;94A:7-12.

30. Ford TF, Butcher DN, Masters JR, Parkinson MC. Immunocytochemical Localisation of Prostate-specific Antigen: Specificity and Application to Clinical Practice. Br J Urol 1985;57:50-55.

31. Epstein Jl, Egevad L, Humphrey PA, Montironi R; Members of the ISUP Immunohistochemistry in Diagnostic Urologic Pathology Group. Best practices recommendations in the application of immunohistochemistry in the prostate: report from the International Society of Urologic Pathology consensus conference. Am J Surg Pathol 2014;38:e6-e19.

32. Torenbeek R, Lagendijk JH, Van Diest PJ, Bril H, van de Molengraft FJ, Meijer CJ. Value of a panel of antibodies to identify the primary origin of adenocarcinomas presenting as bladder carcinoma. Histopathology 1998;32:20-27.

33. Woodard AH, Yu J, Dabbs DJ, Beriwal S, Florea AV, Elishaev E, Davison JM, Krasinskas AM, Bhargava R. NY-BR-1 and PAX8 Immunoreactivity in Breast, Gynecologic Tract, and Other CK7+ Carcinomas: Potential Use for Determining Site of Origin. Am J Clin Pathol 2011;136:428-435.

34. Morichetti D, Mazzucchelli R, Lopez-Beltran A, Cheng L, Scarpelli M, Kirkali $Z$, Montorsi F, Montironi R. Secondary neoplasms of the urinary system and male genital organs. BJU Int 2009;104:770-776.

35. Liu H, Shi J, Wilkerson ML, Lin F. Immuno- histochemical Evaluation of GATA3 Expression in Tumors and Normal Tissues: A Useful Immu- nomarker for Breast and Urothelial Carcinomas. Am J Clin Pathol 2012;138:57-64.

36. Gonzalez RS, Wang J, Kraus T, Sullivan H, Adams AL, Cohen C. GATA3 expression in male and female breast cancers: comparison of clinicopathologic parameters and prognostic relevance. Hum Pathol 2013;44:1065-1070.

37. Tong GX, Yu WM, Beaubier NT, Weeden EM, Hamele-Bena D, Mansukhani MM, O'Toole KM. Expression of PAX8 in normal and neoplastic renal tissues: an immunohistochemical study. Mod Pathol 2009;22:1218-1227.

38. Gupta A, Wang HL, Policarpio-Nicolas ML, Tretiakova MS, Papavero V, Pins MR, Jiang Z, Humphrey PA, Cheng L, Yang XJ. Expression of AlphaMethylacyl-Coenzyme A Racemase in Nephrogenic Adenoma. Am J Surg Pathol 2004;28:1224-1229.

39. Sim SJ, Ro JY, Ordonez NG, Park YW, Kee KH, Ayala AG. Metastatic renal cell carcinoma to the bladder: a clinicopathologic and immunohistochemical study. Mod Pathol 1999;12:351-355. 